\title{
СТАТЬИ
}

УДК 159.99

\section{ОБ ИССЛЕДОВАНИЯХ ПСИХОЛОГИЧЕСКОЙ БЕЗОПАСНОСТИ ЛИЧНОСТИ СОТРУДНИКА МЧС РОССИИ}

\section{Синякова М.Г., Шевелева И.Г.}

Уральский институт Государственной противопожарной службы МЧС России,

Екатеринбург, e-mail:msinykova@yandex.ru

\begin{abstract}
На основе уже имеющихся социально-психологических исследований авторы рассматривают условия психологической безопасности личности сотрудника МЧС с точки зрения обеспеченности психологической безопасности среды, в которой осуществляется его деятельность, и с точки зрения выявления составляющих его внутренних возможностей, обеспечивающих психологическую безопасность сотрудника МЧС. Психологическая безопасность личности сотрудника МЧС в контексте социальной безопасности определяется практическим отсутствием безопасной среды профессиональной деятельности. Этот уровень психологической безопасности обеспечивается профессиональным отбором и профессиональным обучением специалистов экстремального профиля, а также постоянным повышением уровня социальной защищенности спасателей. Психологическая безопасность профессиональной среды для сотрудников МЧС России на мезосоциальном уровне изучается в основном в контексте проблем взаимодействия коллектива спасателей, пожарных, его сплоченности, степени доверия друг другу. В меньшей степени в исследованиях отражена проблема влияния семейных отношений на психологическую безопасность данной категории сотрудников. Микросоциальный уровень исследований психологической безопасности сотрудников МЧС на сегодняшний день затрагивает в основном проблематику выявления и сохранения индивидуально-психологических особенностей специалистов экстремального профиля, обуславливающих их психологическую устойчивость и профессиональную эффективность, а также влияние методов саморегуляции и психологической поддержки на сохранение профессионального здоровья. Вместе с тем не учитывается комплексность индивидуально-психологических, личностных и социально-психологических (субъектность) качеств личности, определяющих ее психологическую безопасность.
\end{abstract}

Ключевые слова: психологическая безопасность личности, психологическая безопасность среды, деятельность сотрудника МЧС России

\section{THE HEALTH OF THE PSYCHOLOGICAL LYSS OF THE STAFF OF THE MINISTRY OF EMERGENCY SITUATIONS RUSSIA}

\author{
Sinyakova M.G., Sheveleva I.G. \\ Ural Institute of the State Fire Service of the Ministry of Emergency Situations of Russia, \\ Yekaterinburg, e-mail: msinykova@yandex.ru
}

On the basis of the available socio-psychological studies, the authors consider the psychological security of the person of the FEMA officer in terms of providing psychological security in the environment in which he is carried out activities, and in terms of identifying the components of its internal capabilities that ensure the psychological safety of the FEMA officer. Psychological security of the identity of an FEMA employee as part of social security and as a result of social relations is determined by the virtual absence of a safe professional environment. This level of psychological security is provided by professional selection and professional training of extreme specialists; and the constant improvement in the level of social security for rescuers. Psychological safety of the professional environment for employees of the Ministry of Emergency Situations of Russia at the mesosocial level is studied mainly in the context of the problems of interaction of the team of rescuers, firefighters, its cohesion, the degree of trust to each other. To a lesser extent, the studies reflect the problem of the impact of family relationships on the psychological safety of this category of employees. The microsocial level of research on the psychological safety of FEMA employees, to date, mainly affects the problem of identifying and preserving the individual-psychological features of extreme specialists, their psychological resilience and professional effectiveness, as well as the impact of self-regulation and psychological support on the preservation of professional health. At the same time, the complexity of individual-psychological, personal and socio-psychological (subjectivity) qualities of the personality that determine her psychological security is not taken into account.

Keywords: Psychological security of the person, Psychological safety environment, Russian Emergencies Ministry employee

В имеющихся психологических исследованиях феномен психологической безопасности личности рассматривается на макросоциальном, мезосоциальном и микросоциальном уровнях [1]. В современной научной действительности возникла потребность в комплексных исследованиях, направленных на всестороннее и разноаспектное рассмотрение психологической безопасности личности, в том числе и в условиях экстремальных ситуаций. Центральным направлением таких исследований может стать выявление личностного ресурса психологических возможностей человека, интегративно обеспечивающих его безопасность. Если говорить об отечественной психологии, то структурно безопасность чаще всего представлена в двух аспектах: психо- 
логическая безопасность среды и психологическая безопасность личности.

Цель исследования: выявить теоретическим путем условия психологической безопасности личности сотрудника МЧС с точки зрения обеспеченности психологической безопасности среды, в которой осуществляется его деятельность, и с точки зрения выявления составляющих его внутренних возможностей, обеспечивающих психологическую безопасность сотрудника МЧС.

\section{Материалы и методы исследования}

Исследование проводилось на основе теоретических и практических изысканий, посвященных изучению феномена психологической безопасности сотрудников МЧС на различных уровнях. Авторы опирались на общетеоретические методы: анализ теоретических и научно-практических источников, обобщение, синтез.

\section{Результаты исследования и их обсуждение}

Известно, что макросоциальный уровень изучения проблемы психологической безопасности личности рассматривается в контексте социальной безопасности, возникающей как результат социальных отношений.

В контексте понимания того, каким образом социальная среда является зоной безопасности для сотрудников МЧС России, попробуем разобраться с понятием «социальная безопасность».

Социологи понятие «социальная безопасность» часто отождествляют с понятием «национальная безопасность». В данном контексте социальная безопасность определяется непосредственно в связи со стабильностью и устойчивостью всей системы социальной защиты населения; а также в контексте способности самой системы социальной защиты к целенаправленному саморегулированию, развитию и совершенствованию. Кроме того, специалисты отмечают, что безопасность в обществе связана со следующими показателями: стабильность заработной минимальной платы и ее соответствие прожиточному социальному минимуму; безопасность труда; социального партнерства; уровень социального обеспечения и социального страхования; степень развития социальной сферы и т.д. [2].

Подчеркнем и тот аспект, что социальная безопасность личности непосредственно зависит от складывающихся взаимоотношений в системе «личность - общество», отражающих как способность каждой личности адаптироваться в обществе, так и способность не быть объектом манипулирования со стороны разнообразных сил и структур, а проявлять себя в качестве субъекта социального творчества [3].

В этой связи мы понимаем, что социальная безопасность личности сотрудника МЧС России будет связана с национальной безопасностью нашей страны. И все трудности ее реализации на данном этапе они будут испытывать на себе, как и все граждане РФ.

Вместе с тем социальная безопасность сотрудников МЧС России определяется и спецификой их профессиональной деятельности, поскольку имеет свои особенности и с точки зрения обеспеченности безопасных условий труда, и с точки зрения социальной обеспеченности.

Профессиональная специфика труда пожарных и спасателей состоит в том, что этот труд относится к категории опасных профессий. К данной категории профессии спасателей, пожарных относятся, прежде всего, из-за неблагоприятных условий труда. Ведущими из них являются:

- угроза здоровью и жизни самих спасателей, пожарных;

- понимание того, насколько от их профессиональной деятельности, реализуемой в экстремальных условиях, зависит жизнь спасаемых людей,

- высокая степень неблагоприятного развития чрезвычайных ситуаций, выраженная в разнообразных факторах: наличие или возможность взрывов, обрушений и завалов, выполнение работы в условиях значительных физических и тепловых перегрузок и информационного дефицита.

Все это в совокупности и определяет сложность и экстремальность профессиональной деятельности сотрудников МЧС [4].

Кроме того, с психологической точки зрения условия профессиональной деятельности пожарных, спасателей характеризуются сильным психотравмирующим воздействием на психику. Психологический стресс - неотъемлемая часть всех чрезвычайных и экстремальных ситуаций, на предупреждение и ликвидацию которых направлена профессиональная деятельность пожарных и спасателей. Необходимо подчеркнуть, что возникающее психотравмирующее воздействие может быть значительным, но однократным, но может быть и интенсивным, и многократным. В последнем случае успешность деятельности при таком воздействии потребует определенного времени на адаптацию к подобному роду источникам стресса. Именно поэтому все сотрудники МЧС России относятся к группе повышенного риска возникновения «посттравматических стрессовых расстройств»особого рода психических нарушений [5]. 
В таких профессиональных условиях речь не идет о какой-либо безопасности. В этой связи специалисты подчеркивают важность и актуальность профессионального отбора и профессионального обучения специалистов экстремального профиля. Среди актуальных направлений исследований в этой области называют:

- определение взаимообусловленности психологической устойчивости и поддержания физической формы сотрудников;

- возможности и механизмы параллельного развития сознания и практической деятельности;

- выявление согласованности физиологических механизмов готовности и уровней регуляции поведения;

- изучение влияния способов поддержания эмоционально-волевой устойчивости на эффективность выполнения боевых задач [6].

Важно подчеркнуть, что МЧС России уделяет особое внимание дополнительным мерам, направленным на обеспечение социальной защищенности, повышение комфортных условий труда и службы личного состава своего ведомства [7]. Актуальность этого вопроса, несомненно, связана с тем, что в своей трудовой деятельности пожарные, спасатели постоянно сталкиваются с реальными профессиональными рисками. В этой связи меры по повышению уровня социальной защищенности спасателей становятся тем социальным фактором, который обеспечивает их психологическую безопасность на макросоциальном уровне и демонстрирует социальное отношение к специалистам экстремального профиля.

Имеющиеся исследования по выявлению особенностей проявления психологической безопасности личности на мезосоциальном уровне посвящены, чаще всего, вопросам взаимодействия личности с ближайшим социальным окружением (социальная, организационная и даже техногенная среда обитания). Нужно отметить, что практически нет исследований, связанных с изучением таких факторов психологической безопасности, как семья и особенности взаимоотношений в семье, значимая для индивида группа.

Вместе с тем значимость коллективной профессиональной деятельности пожарных подчеркивал еще в 80-х гг. прошлого столетия Самонов А.П. [8]. В своих работах он подчеркивает, что профессиональная деятельность пожарных обусловливает необходимость высокой сплоченности коллектива и готовности к активным совместным боевым действиям.

В данном контексте речь идет о том, что в условиях проявления солидарности с коллективом, дружеских взаимоотношений и взаимной помощи, взаимовыручки у пожарных и спасателей возрастает уверенность в успешности выполнения боевой задачи.

В начале нынешнего века появился ряд исследований, которые также указывают на то, что профессиональное взаимодействие влияет на социальные аспекты психологической безопасности сотрудников МЧС (Легошин В.Д., Запорожец А.И., 2007; Мухлынина О.В., 2014; Хмыров И.М., Ященко А.А., Чапля Ю.С., 2014; Холуева К.А., Мухарлямова А.Ю., 2014).

Легошин В.Д., Запорожец А.И. подчеркивают значимость сплоченности команды спасателей и ее командира (лидера), а также общий социально-психологический климат в команде для формирования внутренней (психологической) уверенности в успешности выполнения боевой задачи [9]. Холуева К.А., Мухарлямова А.Ю. в своих исследованиях считают, что отношения к коллегам по работе и знание особенностей членов коллектива пожарных должны рассматриваться как показатели социальнопсихологического климата в коллективе пожарных, спасателей [10].

Сергеев И.Н. в своем диссертационном исследовании указывает, что в целом психология деятельности коллективов подразделений и служб МЧС России находится сегодня на начальном этапе формирования. Поэтому и феномен психологической подготовки коллектива для работы в условиях чрезвычайных ситуаций пока мало изучен [11]. При этом Сергеев И.Н. психологическую подготовку коллектива подразделения к работе в условиях чрезвычайных ситуаций, как и большинство специалистов, связывает с развитием способностей человеческой психики к принятию решений в условиях стресса.

Исследования Мухлыниной О.В. выявили взаимосвязь между уровнем групповой сплоченности и уровнем удовлетворенности работой: чем выше сплоченность в коллективе, тем выше степень взаимопонимания и удовлетворенности трудом сотрудников МЧС. При этом исследователь указывает на зависимость сложившегося характера коллективного обслуживания и правильного использования техники в процессе труда от уровня служебно-профессионального взаимопонимания и эмоциональной удовлетворенности общением и работой в группе [12].

Исследуя психологические факторы гибели и травматизма личного состава спасательных служб, Хмыров И.М., Ященко А.А., Чапля Ю.С. подчеркивают, что со- 
циально-психологические детерминанты, а также проблемы профессиональной коммуникации и адаптации входят в состав основных психологических причин гибели и травматизма спасателей. Кроме того, данная группа исследователей установила, что факты гибели и травматизма чаще наблюдаются среди работников, не имеющих собственной семьи [13]. Нужно отметить, что исследований, связанных с влиянием семейных отношений сотрудников МЧС России на их психологическую безопасность, на сегодняшний день практически нет.

Изучение собственно психологической безопасности личности происходит именно на микросоциальном уровне исследования данного феномена. На этом уровне рассматриваются такие проблемы, как:

- психическая устойчивость индивида в экстремальной деятельности;

- адаптация человека к неблагоприятным условиям труда и существования;

- способность к сопротивлению неблагоприятным факторам природной, техногенной или социальной среды, которая стимулирует переживание чувства своей защищённости.

Несмотря на актуальность заявленных проблем, исследований в этой области явно недостаточно.

В целом исследователи психологическую безопасность личности рассматривают как состояние динамического баланса отношений субъекта к миру, себе, другим, его активности и удовлетворенности в соответствии с тем влиянием, которое оказывают на данный момент условия (в том числе угрожающие) внешнего и внутреннего мира [14].

Доминирующим среди базовых критериев безопасности является физическая целостность человека, обуславливающая его функциональное здоровье [15]. В качестве базовых критериев психологической безопасности достаточно часто называют как ситуационно проявляющиеся индивидуально-психологические особенности человека, так и индивидуальный опыт человека.

Подчеркивая важность функционального здоровья, исследователи вводят понятие «Психологическое здоровье», включающее в себя:

- психические процессы, которые отражают адекватность психического отражения действительности, адекватное восприятие самого себя, способность концентрации внимания, удержание информации в памяти, способность к логической обработке информации, критичность мышления, креативность;

- психические состояния, выраженные эмоциональной устойчивостью, владени- ем негативными эмоциями (страх, гнев) и естественным проявлением чувств;

- свойства личности, определяющие ее здоровье: оптимизм, сосредоточенность, уравновешенность, адекватный уровень притязаний, чувство долга, уверенность в себе, доброжелательность, самоуважение, адекватная самооценка, самоконтроль, целеустремленность и др. [15].

В таком контексте психологическое здоровье способствует целостному и адекватному противостоянию личности различного рода угрозам, что способствует ее психологической безопасности.

В исследованиях сегодня встречаются понятия «безопасная личность» (обладающая качествами, необходимыми для обеспечения собственной безопасности в социуме) и «личность, предрасположенная к опасности». Последнее понятие сегодня активно изучается и используется в виктимологии.

В этой связи мы отметим, что профессиональный отбор в системе МЧС направлен в том числе и на то, чтобы выявить особые качества личности, способной противостоять опасностям. Прежде всего, речь идет о выявлении ряда индивидуально-психологических особенностей человека, обуславливающих психологическую устойчивость личности [16]. И исследований в этой области достаточно много.

Вместе с тем качества безопасной личности, по мнению специалистов, несколько шире [17]. Они считают, что индивидуально-психологические качества (среди них критичность мышления, внимательность, преобладание волевой сферы, эмоциональная устойчивость), личностные качества (в т.ч. адекватная самооценка, самоактуализация, рефлексия, высокий уровень самосознания) и социально-психологические качества личности во многом определяют не только степень осознания экстремальной ситуации, но и адекватность поведения в такой ситуации.

Достаточное количество исследований посвящено выявлению зависимости переживания собственной безопасности в чрезвычайной ситуации от способности личности к саморегуляции [18; 19]. Отметим, что к факторам, детерминирующим способность к саморегуляции, относят:

биологические свойства человека (бессознательная регуляция);

индивидуальные особенности психического отражения и психических функций человека;

опыт, навыки, знания; направленность человека и т.п. [20].

Механизмы саморегуляции специалисты рассматривают в качестве профилакти- 
ческих средств сохранения профессионального здоровья.

\section{Выводы}

1. Психологическая безопасность личности сотрудника МЧС в контексте социальной безопасности определяется и спецификой их профессиональной деятельности, поскольку имеет свои особенности и с точки зрения обеспеченности безопасных условий труда, и с точки зрения социальной обеспеченности. В этой связи меры по повышению уровня социальной защищенности спасателей становятся тем социальным фактором, который обеспечивает их психологическую безопасность на макросоциальном уровне и демонстрирует социальное отношение к специалистам экстремального профиля. Кроме того, в этом контексте возрастает актуальность профессионального отбора и профессионального обучения специалистов экстремального профиля.

2. Имеющиеся психологические исследования, посвященные выявлению особенностей проявления психологической безопасности личности на мезосоциальном уровне, направлены в основном на изучение взаимодействия коллектива сотрудников МЧС, его сплоченности, степени доверия друг другу. В меньшей степени в исследованиях отражена проблема влияния семейных отношений на психологическую безопасность данной категории работников.

3. Микросоциальный уровень исследований психологической безопасности сотрудников МЧС на сегодняшний день затрагивает в основном проблематику выявления и сохранения индивидуально-психологических особенностей специалистов экстремального профиля, обуславливающих их психологическую устойчивость и профессиональную эффективность, а также влияния методов саморегуляции и психологической поддержки на сохранение профессионального здоровья. Вместе с тем не учитывается комплексность индивидуально-психологических, личностных и социально-психологических (субъектность) качеств личности, определяющих ее психологическую безопасность.

\section{Список литературы}

1. Синякова М.Г., Кошкаров В.С. Теоретические аспекты изучения проблемы психологической безопасности личности // Техносферная безопасность. 2015. № 3(8). С. 68-74.

2. Манукян А.В. Социальная безопасность как предмет социологического исследования // Государственное и муниципальное управление. Ученые записки СКАГС. 2017. № 2. C. $225-228$
3. Шиловцев А.В. Социальная безопасность личности в современной России // Вестник ПНИПУ. Социально-экономические науки. 2018. № 1. С. 96-106.

4. Зиньковская С.М. Системное изучение человеческого фактора в опасных профессиях: автореф. дис. ... докт. псих. наук: 19.00.01. Москва, 2007. 45 с.

5. Громова О.Н., Писарева А.И. Перспективы повышения уровня социальной защищенности спасателей // Молодой ученый. 2018. № 49. С. 205-206.

6. Комаров К.Э. Психологическая подготовка к действиям в условиях повышенного риска: учебно-методическое пособие («стресс-менеджмент»). Часть 1. М., 2010.96 с.

7. Есавкина Н.А., Винокурова Н.Г., Малыгина Е.А. Педагогические аспекты профессиональной подготовки сотрудников специальных подразделений федеральной противопожарной службы МЧС России к действиям в условиях чрезвычайной ситуации // Вестник Санкт-Петербургского университета Государственной противопожарной службы МЧС России. 2016. № 3. С. 127-133

8. Самонов А.П. Психологическая подготовка пожарных. М.: Стройиздат, 1982. 79 с.

9. Легошин В.Д., Запорожец А.И. Научно-методические вопросы профессионального отбора и подготовки спасателей МЧС России // Технологии гражданской безопасности. 2007. № 1. С. 16-21.

10. Холуева К.А., Мухарлямова А.Ю. Социально-психологический климат в коллективе пожарных // Современные проблемы науки и образования. 2014. № 3. [Электронный pecypc]. URL: http://science-education.ru/ru/article/ view?id=13334 (дата обращения: 28.03.2020).

11. Сергеев И.Н. Совершенствование психологической подготовки коллективов МЧС России к работе в условиях чрезвычайной ситуации: автореф. дис. ... канд. психол. наук. Санкт-Петербург, 2010. 23 с.

12. Мухлынина О.В. Изучение сплоченности и ценностных ориентаций у сотрудников МЧС // Личность в профессионально-образовательном пространстве: материалы XIII Всероссийской научно-практической конференции (г. Екатеринбург, 21 ноября 2014 г.). Екатеринбург: Рос. гос. проф.-пед. ун-т., 2014. С. 97-100.

13. Хмыров И.М., Ященко А.А., Чапля Ю.С. Психологические факторы гибели и травмирования личного состава спасательных служб // Пожарная безопасность: проблемы и перспективы. 2014. № 1 (5). С. 159-161.

14. Лызь Н.А. Развитие здоровой и безопасной личности в образовании: Психолого-педагогические основы: монография. Saarbrucken, Germany: LAP LAMBERTAcademic Publishing GmbH \& Co. KG, 2012. 246 p.

15. Фролова Ю.Г. Психология здоровья: пособие. Минск: Вышэйшая школа, 2014. 255 с.

16. Есавкина Н.А., Винокурова Н.Г., Малыгина Е.А. Педагогические аспекты профессиональной подготовки сотрудников специальных подразделений федеральной противопожарной службы МЧС России к действиям в условиях чрезвычайной ситуации // Вестник Санкт-Петербургского университета Государственной противопожарной службы МЧС России. 2016. № 3. С. 127-133.

17. Эксакусто Т.В. Теоретические основы социальнопсихологической безопасности: монография. Ростов н/Д.: Изд-во Южного федерального ун-та, 2010. 343 с.

18. Шленков А.В. Психологическое обеспечение профессиональной подготовки сотрудников Государственной противопожарной службы МЧС России: автореф. дис. ... докт. псих. наук. Санкт-Петербург, 2010. 43 с.

19. Сочнев В.Н., Сочнева И.В. Саморегуляция сотрудников МЧС: приемы и методы // Вестник российских университетов. Математика. 2011. № 1. С. 332-335.

20. Тарас А.Е., Сельченок К.В. Психология экстремальных ситуаций: Хрестоматия. М.: Издательство: АСТ; Минск: Харвест, 2002. 480 c. 